\title{
Editorial
}

\section{LA SALUD MENTAL DEL PERSONAL DE SALUD ANTE EL COVID-19}

\author{
Homo sum, humani nihil a me alienum putat \\ (Hombre Soy por lo tanto nada de lo humano me es ajeno)
}

Algunos medios alertaron que El Salvador, a inicios de la pandemia en el año 2020, tenía una de las más altas letalidades de la región centroamericana en su personal de salud -algunos estudios incluso sugirieron una tasa próxima al $9 \%$-, principalmente, entre los médicos pertenecientes a grupos etarios de mediana edad ${ }^{2}$.

La perspectiva ante el COVID-19, por parte del personal de salud, ha sido parecida a la de la sociedad en general, miedo a infectarse o a infectar a familiares y amigos. El conocimiento de la patología asociada a la infección por el virus y los medios de protección fueron evolucionando a un ritmo menor que la misma pandemia.

En una encuesta administrada en Estados Unidos, al inicio de la pandemia por COVID 19, arrojó diferentes causas de ansiedad entre el personal médico: «acceso a equipo de bioseguridad apropiado; llevar la infección a su familia; no tener acceso rápido a prueba confirmatorias si se tuviesen síntomas; diseminar el virus en el trabajo; incertidumbre sobre si se contaría con apoyo institucional en caso de presentar la enfermedad (el profesional expuesto o su familia); y falta de acceso a información y comunicación científica fidedigna y actualizada» ${ }^{3}$.

1 Doctor en medicina, Vicerrector de Investigación y Proyección Social, dario.chavez@uees.edu.sv, ORCID https://orcid. org/0000-0002-0394-1178

2 https://actbistas.org/el-salvador-tiene-la-letalidad-por-covid-19-en-medicos-mas-alta-en-centroamerica/

3 Understanding and Addressing Sources of Anxiety Among Health Care Professionals During the COVID-19 Pandemic disponible en https://jamanetwork.com/journals/jama/fullarticle/2764380 
En cuanto a la situación del personal de salud en El Salvador hay pocos estudios y programas sistematizados, aunque si está documentado en otros países y latitudes ${ }^{4}$

El personal de salud y el médico particularmente en términos generales se ve inmerso en una cultura laboral altamente competitiva que muchas veces lo hace aferrarse a una imagen de fortaleza e «inmunidad» ante el riesgo de enfermar, con una perspectiva de autoriesgo muchas veces minimizada por él mismo o sus compañeros ${ }^{5}$. Es indudable que la profesión médica es altamente demandante, pero ello no significa que debe ser una suerte de prueba de quien resiste más o se trate de «selección natural» del más apto.

El médico tiene poco o casi nada interiorizada la necesidad del autocuido, en ese sentido, difícilmente buscará un grupo de autoayuda (apoyo emocional, psicológico o espiritual) con el propósito de expresar sus emociones de confusión, miedo, culpa, tristeza, insensibilidad o enojo. Muchas veces a un ambiente sobrecargado laboralmente se le suma maltrato sistematizado entre profesionales y entre estos y médicos en formación. Además, la pandemia por COVID-19, tuvo características de impredecibilidad del pronóstico de quienes la padecen, poca certeza de quienes eran portadores asintomáticos y el número de sospechosos que la desarrollarían. Asimismo, los casos confirmados se crecían alarmantemente hasta evolucionar a cuadros sintomáticos, hasta los casos de intubación o muerte; todo lo anterior, sin duda, desembocó en un incremento infravalorado y de subregistro por falta de conciencia de su importancia, presentación o agudización de trastornos mentales, alcoholismo, drogadicción, trastornos del estado del ánimo, ansiedad, depresión, intento suicidio o incluso suicidio.

Otro efecto asociado al que poco se le presta atención es el estrés que se presenta por un periodo determinado y con diferente intensidad. Puede aparecer sin trastorno mental previo o empeorar alguna condición preexistente. El riesgo de este problema, se incrementa si se le añade cansancio físico o patologías orgánicas ${ }^{6}$. También influyen la capacidad de adaptación y resiliencia de cada persona. Los síntomas pueden ser variables, generalmente aparece como primera manifestación un «embotamiento u ofuscamiento», con reducción de la concentración y desorientación. De este estado puede pasarse hasta el grado de estupor disociativo o a una agitación e hiperactividad, en la mayor parte de los casos, también están presentes signos vegetativos propios de los ataques de pánico (taquicardia con sensación de palpitaciones, sudoración excesiva y rubicundez).

\footnotetext{
$4 \quad$ Programa Atención Integral al Médico Enfermo - PAIME, Madrid, España.

5 https://www.medigraphic.com/pdfs/medcri/ti-2020/ti203e.pdf

$6 \quad J o h n$ W. Barnhill, MD, Weill Cornell, Trastorno por estrés agudo Medical College and New York Presbyterian Hospital. Disponible en https://www.msdmanuals.com/es/hogar/trastornos-de-la-salud-mental/ansiedad-y-trastornos-relacionadoscon-el-estr\%C3\%A9s/trastorno-por-estr\%C3\%A9s-agudo
} 
El Síndrome de Burnout ocupacional ocurre por tensión crónica, asociada al estrés del lugar de trabajo. Se caracteriza por: a) agotamiento; b) sentimientos negativos en relación con el trabajo; c) efectividad laboral reducida. El síndrome de agotamiento ocupacional se refiere específicamente a los fenómenos en el contexto laboral que afectan la productividad y calidad de vida.

Esta condición puede pasar desapercibida debido a las presiones laborales, la normalización de la explotación laboral o la cultura laboral en donde del personal de salud no debe revelar las inconformidades o inquietudes para no afectar su estabilidad laboral. Es urgente, por lo tanto, que la detección oportuna e intervención sea cada vez más visible y se convierta en parte de la agenda en las instituciones de salud. ${ }^{7}$

Otro aspecto poco documentado en nuestro país es el acoso sexual y acoso (o mobbing) laboral. El mobbing es un tipo de violencia psicológica en el trabajo, identificado por conductas de acoso, daño psíquico, intencionalidad premeditada.

Esta situación se manifiesta cuando un trabajador es amenazado o acosado por sus compañeros; como dato curioso, no solo proviene de los superiores, si no puede venir, precisamente, de los subordinados a jefes o entre pares ${ }^{8}$. El mobbing y acoso sexual en el personal médico puede ser un estresor significativo, sobre todo, para las mujeres y otros grupos vulnerables.

Como signos de alarma podemos citar: cambios en la personalidad: distrés, tristeza, ira, hostilidad, expresiones de desvalorización o desesperanza constante; cambios de conducta: reducción del rendimiento y desempeño; ausencias o retrasos repetidos en actividades importantes, conflictos interpersonales; cambios físicos: deterioro físico, del cuido personal, cambios de peso, astenia, alteraciones del sueño; señales de adiciones; quejas de usuarios y compañeros, ausencias no justificadas, conflictividad fuera del ámbito de trabajo; angustia, expresiones de preocupación.

En resumen, podemos decir que el personal de salud, todos sin excepción, pero particularmente los de primera línea, tienen y han tenido que lidiar, por más de un año, con sendos desafíos en un ambiente en condiciones de poca protección a la salud mental, altas presiones de los pacientes y sus familiares, toma de decisiones complejas y difíciles, ver enfermos o, incluso, morir a compañeros del gremio médico; debiendo convivir con el «fantasma» de una muerte en soledad, mitos y desinformación, aun cuando son el grupo profesional que se supone cuenta con más herramientas científicas.

Dado lo antes expuesto, hubiésemos esperado que la pandemia por el COVID-19 dejara lecciones aprendidas para el Colegio Médico, Instituciones públicas, privadas personal médico, para mayor cuido de la salud física y mental, proveyendo de programas y recursos básicos de atención primaria en salud.

\footnotetext{
7 http://bvs.minsa.gob.pe/local/MINSA/5000.pdf

8 http://www.scielo.org.pe/scielo.php?script=sci_arttext\&pid=\$1728-59172016000200015
} 


\section{¿Qué debe hacerse?}

\section{- Completar el esquema de vacunación contra COVID-19 y seguir con medidas de bioseguridad}

El programa de vacunación en El Salvador ha sido una estrategia completa diseñada e implementada de forma articulada por diferentes instituciones del Gobierno, con la que se busca agilizar el proceso de protección ante el coronavirus 9 . No obstante, las medidas de bioseguridad no pierden su vigencia, sobre todo, para el personal de primera línea, expuesta probablemente a cargas infecciosas significativas.

\section{- Reforzar el sistema de salud con programas sistematizados promoción y atención en salud mental de profesionales de la salud}

Capacitar a los tomadores de decisiones a ejercitar estilos de dirección situacionales, uso de técnicas actualizadas, dejar perspectivas obsoletas o de la vieja escuela administrativa.

Estos programas deben ser accesibles, confidenciales y gratuitos. Deben estar normados por políticas y lineamientos técnicos. Los programas de salud deben ser integrales, e incluir los diferentes niveles de prevención primaria, es decir, mejorar las condiciones para su prevención, y residencia, trabajo en equipo y gremialidad bien entendida; prevención secundaria, para el diagnóstico oportuno y tratamiento efectivo ${ }^{10}$.

\section{- Resolución de conflictos y prevención del maltrato médico}

Hasta ahora no hay estudios o los hay pocos y tímidos que evidencien los conflictos y el maltrato médico. La «vieja escuela» implica que el médico debe imponer su liderazgo demostrando superioridad ante una competitividad desleal que varia entre grupos y a lo largo del tiempo. El médico en formación no tiene derechos; en el pasado no era extraño usar términos que se consideraban cómicos como «pellejines» o «torundas»; castigos frecuentes tipo militar, y de igual manera una marcada rivalidad fomentada entre graduados de la Universidad de El Salvador (Universidad Nacional) y universidades privadas (quizás esto ha mejorado en alguna medida, pero sin dudas hay resabios).

El médico no está formado en técnicas para la resolución de conflictos, ni hay leyes o normativos que se apliquen de manera sistemática para proteger a los más débiles.

\section{- Autocuido básico}

El autocuido es la capacidad de auto promoción de la salud individual; prevenir enfermedades, afrontar problemas de salud-enfermedad y discapacidades tanto como sea posible, contando o no con el apoyo de profesionales de la salud. ${ }^{11}$

\footnotetext{
9 https://www. presidencia.gob.sv/plan-de-inmunizacion-contra-covid-19-implementado-por-el-gobierno-del-presidentenayib-bukele-avanza-para-el-beneficio-de-policias-militares-docentes-y-bomberos/

10 https://www.cedhnl.org.mx/imagenes/publicaciones/presentaciones/CEDHNL_VIISeminarioDHS/ModuloIV/SALUD-MENTALEN-PROFESIONALES-DE-LA-SALUD.pdf

11 Guía Técnica, Cuidado de la Salud Mental del personal de la salud en el contexto del COVID - 19 disponible en http://bvs. minsa.gob.pe/local/MINSA/5000.pdf
} 
Como parte del entrenamiento recibido por el personal de salud, se le suele inculcar que como profesional médico siempre ha de estar disponible para otros, siendo secundarias sus propias necesidades ${ }^{12}$ Esto, aunque en muchos médicos es un verdadero gesto de altruismo y cumplimiento del juramento Hipocrático, para otros representa imponerse de manera individualista y competitiva, en todo caso, conlleva, incluso, no comer, descanso insuficiente, entre muchos otros. Por lo tanto, el personal de salud, debe asegurarse de comer, beber y dormir regularmente. No hacerlo pone en riesgo su salud mental y física; también, puede comprometer su capacidad para atender a los pacientes. Las técnicas de respiración, atención plena, el ejercicio físico... pueden ser útiles para la desactivación emocional, fisiológica y/o cognitiva.

\section{Compartir información y evidencia científica y mensajes positivos}

Debe comunicarse a colegas información científica clara y alentadora. Identificar y exponer errores, o incidentes médicos de cara a superarlos y aprender de ellos, sin intención punitiva. Los elogios y encomios son motivadores importantes que refuerzan la autoestima y seguridad, reduciendo la tensión permanente del día a día. Compartir fracasos que generen frustración y buscar alternativas de solución ${ }^{13}$.

La resolución de problemas es una habilidad profesional que proporciona una sensación de logro incluso para pequeños incidentes, fomentar el trabajo en equipo y el fortalecimiento mutuo. Participar en actualizaciones de conocimiento para mantenerse informado de la situación: planes y políticas.

Realizar actividades de ocio y esparcimiento, en la medida de las posibilidades (lectura, juegos de mesa, películas, actividad física, alimentación saludable). Hacer planes para la postpandemia.

\section{Organizar una rutina periódica fuera del horario laboral}

Trate de mantener los hábitos que permitan las medidas de restricción, como el cambio de hábitos es muy drástico, explore de forma creativa otras opciones que pueda hacer en aislamiento en casa: rutinas diarias de ejercicio, cuidado físico, lectura, llamar o videoconferencia a seres queridos.

12 Mochila COVID 19, Prevención y Manejo del Estrés Laboral y Desgaste Profesional del Personal Sanitario, ante la Situación de la COVID 19, disponible en https://instituciones.sld.cu/psicologiadelasalud/files/2020/05/15-Profesionales-de-la-salud.pdf

13 Cuidando la Salud Mental del Personal Sanitario, Sociedad Española de Psiquiatría, disponible en http://www.sepsiq.org/file/ InformacionSM/SEP\%20COVID19-Salud\%20Mental\%20personal\%20sanitario.pdf 


\section{Tener consciencia de la emocionalidad: buscar ayuda profesional}

La competencia profesional no es incompatible con las emociones (de hecho, esta es una característica de los seres humanos), como personas somos entes físicos, emocionales, sociales y espirituales, por lo tanto, sujetos a experimentación: confusión, inquietud, descontrol, miedo, culpa, impotencia, tristeza, irritabilidad, insensibilidad, labilidad. Compartir las emociones mediante el lenguaje verbal con otras personas que transmitan seguridad y confianza ayuda a desarrollar más tolerancia, autocontrol y autorregulación.

Las emociones desagradables no son antinaturales sino reacciones del cuerpo ante un peligro, son un mecanismo de defensa. No obstante, pueden derivar en patologías como depresión, insomnio, trastornos obsesivos - compulsivos, etc.

\section{Espacios de ocio y descanso cuando sea posible}

Siempre que sea posible, deben hacerse actividades recreativas saludables, no relacionadas con el trabajo, en las que se encuentre alivio, diversión y relajación. Algunos profesionales podrían percibir culpa si no trabajan permanentemente o si se divierten mientras otros están sobrecargados laboralmente. Otros pueden percibir que su estabilidad laboral y competitividad se menoscaba.

\section{Reconocer la propia vulnerabilidad}

Reconocer signos de estrés, pedir ayuda y aprender a darles importancia buscando atención de los mismos, es un modo de regulación interna que favorece el equilibrio, frente a una contingencia dada. ${ }^{14}$ 